\title{
Bryn Mawr Department Receives Award
}

\author{
Allyn Jackson
}

We have a very positive outlook on doing math. It's inclusive. We don't turn away people because they don't meet an artificial criterion of what one is supposed to be to do math.

- Paul Melvin,

Chair, Bryn Mawr mathematics department

When you open wide the doors to mathematics, a broad spectrum of individuals enters and they find something to engage their minds. Maybe they finally shake off the "math anxiety" that followed them in school. Maybe after a couple of introductory courses they gain appreciation for the usefulness of the field; maybe, their interest piqued, they opt for a minor in math. Maybe for the first time in their lives they realize that mathematics is a field they can love, and they pursue a math major.

The Bryn Mawr mathematics department has such wide-open doors. By cultivating a special atmosphere-fun-loving yet serious, supportive yet challenging - the department has been enormously successful in attracting a diverse group of students. Some are already committed to mathematics and seek out Bryn Mawr as a great place to prepare for graduate school; others never imagined they might actually like mathematics. As a women's college, and as one of the few liberal arts colleges to have a graduate program in mathematics, Bryn Mawr has played a significant role in increasing the participation of women in mathematics. It also offers an example that many other departments can emulate. For its unique profile and outstanding performance, the Bryn Mawr mathematics department has been selected as the 2012 recipient of the AMS Award for an Exemplary Program or Achievement in a Mathematics Department.

\section{Evidence of Success}

The success of the Bryn Mawr mathematics department grows from deep roots. Its graduate program was started almost simultaneously with the founding of the college in 1885. When Emmy Noether fled Europe in 1933, she joined the Bryn

Allyn Jackson is senior writer and deputy editor of the Notices. Her email address is axj@ams.org. DOI: http://dx.doi.org/10.1090/noti850
Mawr faculty. Although she lived only another two years, her intellectual legacy left a profound impact on the college.

Up to the 1970s, the main purpose of the Bryn Mawr mathematics major was preparation for doctoral work. Around that time, the department began making a conscious effort to encourage all students to study as much mathematics as they could. During the 1990s, the number of majors rose to an average of thirteen per year, or about 5 percent of the graduating class. The numbers continued to increase over the succeeding decade, with an average of twenty-seven majors per year between 2001 and 2010-almost 9 percent of the graduating class. Many Bryn Mawr math majors excel in the subject, with about a dozen of them annually taking part in Research Experiences for Undergraduates programs across the country and some continuing on to graduate school. Currently, four Bryn Mawr math major alumnae hold Graduate Research Fellowships from the National Science Foundation.

The Bryn Mawr mathematics department stands out among liberal arts colleges for its research profile. It has a total of six faculty either with tenure or on the tenure track, and all of them are active in research. With a steady-state of just six doctoral students, the graduate program is too small to have been included in the last ranking of graduate programs by the National Research Council. Nevertheless, one can calculate where the department would have landed had it been ranked, and the results are impressive. Its publication rate for the years 2000-2006 was one paper per year per faculty member, which would have placed the department in the top half of ranked departments. The faculty's citation rate of approximately 1.5 citations per paper each year would have been in the top quarter, and in the last few years that rate rose to 2.2 citations per paper per year.

\section{Helping Students Succeed}

The most basic ingredient is that the faculty sincerely want to help students of all levels succeed.

- Victor Donnay,

Bryn Mawr mathematics department 
The Bryn Mawr mathematics faculty is united by a love of mathematics and a desire to open the subject to all students. We "really do believe that a very broad range of students can learn to enjoy and succeed in mathematics," said faculty member Helen G. Grundman. This is in contrast to many mathematics departments, where attention is trained on those students who are "math stars", while others pass through largely unnoticed. "We see potential in a much broader sense and strongly encourage all students to pursue more mathematics," commented faculty member Lisa Traynor. "We have a number of students who are self-proclaimed math nerds, but we also have many in our community who never dreamed they would be math majors."

According to Bryn Mawr alumna Rebecca Rebhuhn-Glanz, now a math graduate student at the University of Michigan, the best thing about the Bryn Mawr mathematics department is the way individual development is prized and nurtured. "[T]he professors, while helping you find your abilities, don't try to push you into a single career path," she commented. "The department trains people who go into various fields of work, and they do very well wherever they are." Bryn Mawr math majors have gone on to successful careers in areas such as teaching, consulting, finance, government, and medicine, as well as on to graduate school in various subjects.

Another key aspect of the department's success is its sense of community. "We have developed a welcoming and supportive community where all members-faculty, graduate students, and undergraduates-have an important role," said Traynor. The students interact in a noncompetitive environment where working together and mutual support are encouraged, and the faculty members put a great deal of personal effort into making all students feel welcome and valued. Indeed, one feels the sense of community when walking the halls of the department; one sees it in the open and lively interactions between faculty and students; one hears it in students' comments about the department. One of them summed it up simply: "The Bryn Mawr math department is a home to me."

\section{Activities, Serious and Silly}

A variety of events bring together the departmental community at Bryn Mawr. One example is the Distressing Mathematics Collective (DMC), which started about fifteen years ago. Grundman and some students dreamed up the idea and the quirky name, which is intended to call to mind those small tidbits of mathematics that distress in their unexpectedness-counterexamples that run against intuition, mind-bending paradoxes, or just results that have a strange twist or are off the beaten track of most mathematics courses. Each week a student talks for thirty to sixty minutes in a

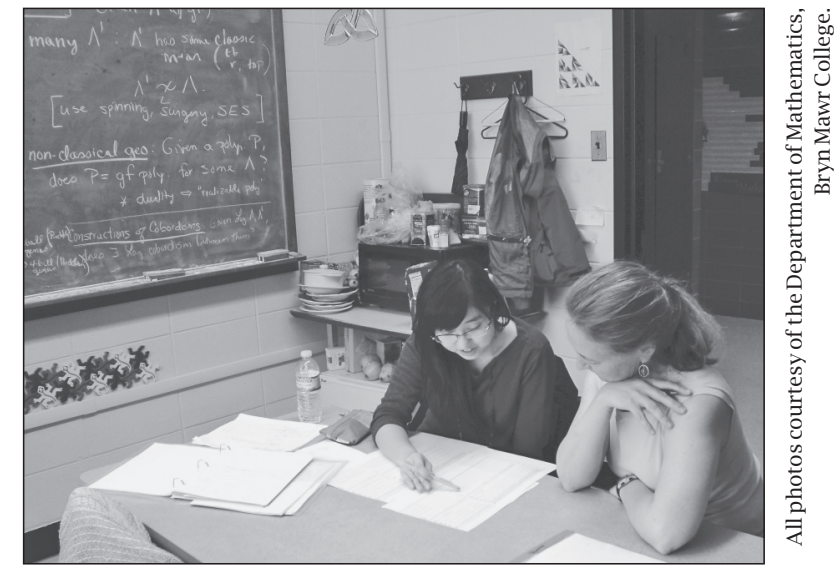

Professor Lisa Traynor (right) in discussion with Shuning Yan' 13.

casual, relaxed atmosphere where jokes, interruptions, and, as Grundman put it, "general silliness," are encouraged. The session usually ends with a game of cards. Despite the lighthearted tone, the DMC has some serious payoffs. Students get exposed to a wide range of mathematics in a friendly atmosphere, and they learn to speak up and ask questions, so that mathematics becomes more than a spectator sport. Those who speak in the DMC have to deal with interruptions, so they learn ways to get and hold the audience's attention. Said Grundman, "More than once, I've heard students who are preparing to give a talk in a class or at a student conference say something like "After giving talks in DMC, I can give a talk anywhere!””

For some activities that are common in mathematics departments, Bryn Mawr has added innovative twists that increase the activities' effectiveness. For example, students are enticed to attend colloquium talks through the offer of bonus course points, which they can obtain by writing a paragraph about the talk. Once a semester, the traditional departmental tea is expanded into an afternoon celebration dedicated to recruiting new majors: Math majors have their pictures taken (the pictures are later posted on a department bulletin board) and mingle with potential majors. In addition to providing career advice to students, each spring the department holds a panel discussion featuring alumnae who speak about how the math major has been useful in their careers.

One successful departmental activity actually has little to do with mathematics: the Mathematics Shakespeare Reading Group. The group meets a few times a year to read a Shakespeare play aloud. To keep seriousness low and fun high, parts are assigned at random so no one can prepare ahead of time. Mathematics enters through the back door: Whenever a word with a mathematical meaning is read-group, ring, field, prime, integral-the readers echo it. The group was started about twenty years ago by a math major who liked to ask, 


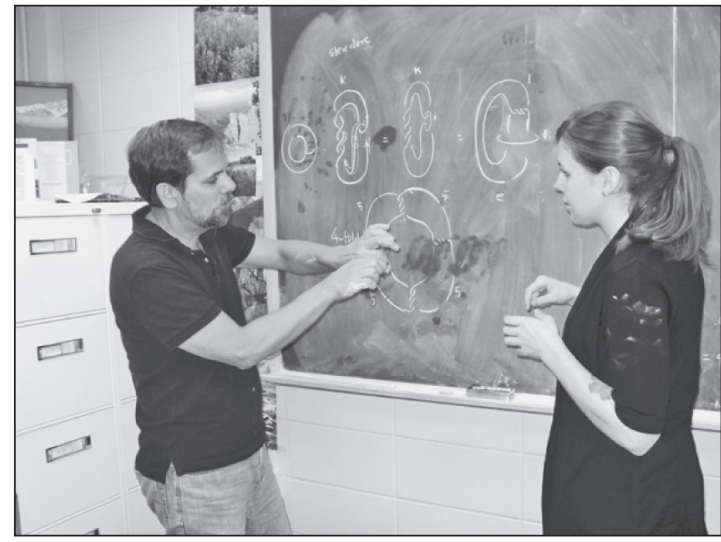

Bryn Mawr chair Paul Melvin (left) at the blackboard with graduate student Laura Mansfield.
"How often do English majors get together to read some algebra?" In fact, the reading group is open to anyone, not just math majors, and attracts a broad range of students.

A few years ago, the Bryn Mawr mathematics department established a student chapter of the Mathematical Association of America. Each year, over twenty math majors become members of the chapter's board of directors and take on such tasks as helping with the Distressing Math Collective, preparing the department newsletter, planning excursions to math conferences, and serving as captain of the department's Putnam Exam Club. The student chapter builds community among the students and gives them a stake in ensuring the success of departmental activities.

\section{Advantages of a Graduate Program}

Not many smaller schools have a serious Ph.D. program in mathematics. Bryn Mawr does, and it has an incredibly positive effect on our undergraduate majors.

\section{- Helen G. Grundman, Bryn Mawr mathematics department}

All the Bryn Mawr mathematics professors are active in research, and they cover a broad swath of the field. Bryn Mawr graduate students therefore can receive training comparable to that at a much larger university, but in a special atmosphereone that is friendlier, more supportive, and less competitive.

In many ways, Bryn Mawr's graduate program is central to the department's identity. For one thing, it makes the department appealing to high-caliber mathematicians. "All of our hires have said that the graduate program is a factor in their coming here," Melvin noted. Bryn Mawr attracts a special breed of mathematician who is dedicated to both teaching and research, though finding time for both is not easy. Melvin noted that the Bryn Mawr mathematicians have coped in part by becoming adept at seizing any opportunity they can to involve students in research. ("And," he conceded, "we don’t get any sleep.")
Another advantage of the graduate program is that highly talented math majors can take graduate courses, so that they get a head start on graduate school. They also have the option of a combined A.B./M.A. program, in which they can write a master's thesis and complete both degrees in four years. The department's doctoral students serve as teaching assistants and work with undergraduates one-on-one and in small groups, allowing for plenty of personal interaction. "This makes it possible for us to have the sort of welcoming, inclusive major that is our goal," Grundman commented. Operating in an environment that values excellent teaching, the graduate students are inspired to take their own teaching seriously. They also serve as role models for undergraduates who are considering graduate work in mathematics.

The success of Bryn Mawr's math graduate program has fed into a national program that has had a substantial impact on the participation of women and minorities in mathematics: the EDGE program. The name stands for Enhancing Diversity in Graduate Education and refers to the idea of helping to give women an "edge" in Ph.D. programs. Founded in 1998 by Rhonda Hughes, now retired from Bryn Mawr, and Sylvia Bozeman, Spelman College, EDGE is geared towards female students-particularly those from underrepresented minority groupswho have excelled in early mathematics courses but may have had limited exposure to advanced mathematics. The aim is to reduce attrition in the first year of graduate school by providing exposure to graduate-level mathematics and to the culture of graduate school, along with a support network and positive feedback. EDGE has since expanded to include "mentoring clusters" that support students through graduate school and beyond. At the time of this writing, a total of forty EDGE alumnae had received Ph.D.s in the mathematical sciences. In 2007 EDGE received the Mathematics Programs That Make a Difference Award, presented by the AMS Committee on the Profession. In 2004 Hughes received the Lifetime Mentor Award from the American Association for the Advancement of Science; Bozeman received it in 2008.

After initially alternating between Bryn Mawr and Spelman, EDGE became a national program by forming partnerships with several colleges and universities, and those institutions have hosted the program since 2003. In addition to Hughes, several Bryn Mawr faculty have been active in EDGE. In the fall of 2011, after thirteen years of running the program, Bozeman and Hughes turned over the directorship to Ami Radunskaya of Pomona College and Ulrica Wilson of Morehouse College, both of whom have had a long association with EDGE.

\section{Educational Innovations}

As the Bryn Mawr mathematics department opened its doors wider to include a greater diversity of 
students, it began to make innovations in its course offerings to better meet students' needs. For example, when the department found that many students were having trouble moving from courses focused on calculation to those focused on proofs, Grundman developed a sophomore-level course called "Transitions to Higher Mathematics", which orients students towards active reading of mathematics and communicating through proofs. To show students that mathematics is not just a collection of techniques but has a special beauty, Melvin and Traynor developed a sophomorelevel course on knot theory. Because many students are interested in applying math to the real world, Leslie Cheng developed courses in financial mathematics, and Victor Donnay revised the differential equations course to include a dynamical systems approach focusing on mathematical modeling for environmental issues. In addition, Donnay taught a service-learning seminar on math and sustainability.

The Bryn Mawr mathematics department also refined its "senior capstone" course. "A lot of colleges struggle with what's right to do with this course," Melvin commented. "Ours seems to work very well." The course, called the "Senior Conference" is organized like a seminar, so that students give lectures and work together in groups-in other words, they receive in-depth practice in communicating about mathematics. "It's a lot of fun, and the students have a say in the direction of the seminar," Melvin commented. For students with a sufficiently strong academic record, there is also the option of writing a senior thesis.

Some Bryn Mawr students are interested in teaching, but the college's small education program has no specialist in mathematics or science. To fill this gap, Donnay developed and teaches regularly a course called "Changing Pedagogies in Math and Science Education". He has also been active in regional and national efforts to improve mathematics education. He was the coprincipal investigator of the Mathematics and Science Partnership of Greater Philadelphia, which aimed to improve math and science education in secondary schools, colleges, and universities. This US\$12 million project, funded by the National Science Foundation, brought together higher education faculty from thirteen institutions and math and science teachers from forty-six school districts. Donnay was coprincipal investigator for a pilot project to support teachers and school districts in teaching environmental sustainability, and this year he is teaching a two-week summer institute for local teachers on math and sustainability.

\section{Winners: Both the Stars and the Struggling}

Bryn Mawr turned me into a mathematician. I owe absolutely everything that I've done mathematically

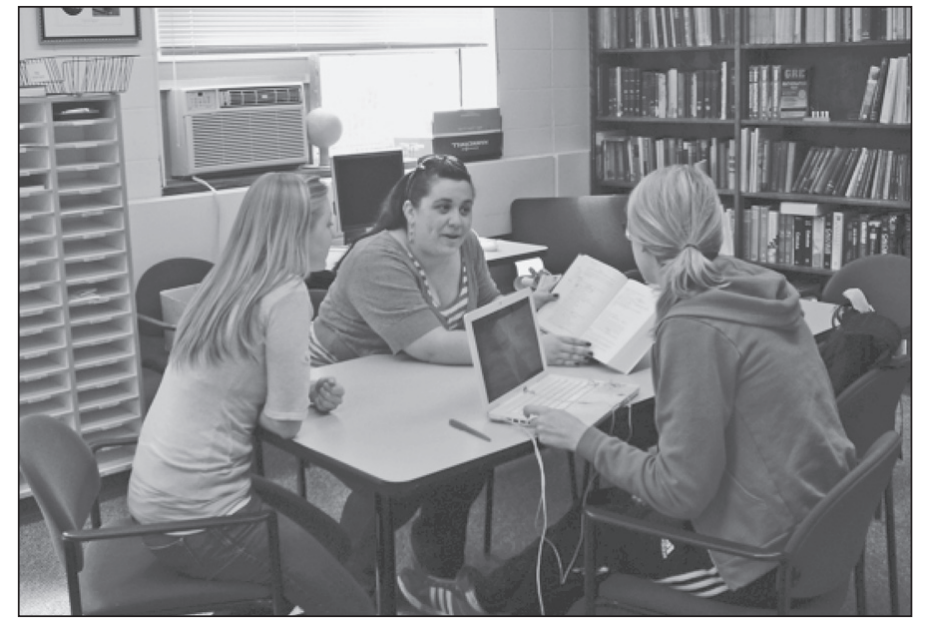

Discussing mathematics are (from left) Meagan Neal '13, Sarah Hockley '1 1, and Katie Link '12.

to the wonderful professors who mentored me there.

\section{- Jaclyn Lang, \\ Bryn Mawr alumna and \\ UCLA math graduate student}

Some of the magic of the Bryn Mawr mathematics department is due to its being in a women's college. “It's a gentler atmosphere," Melvin acknowledged. But he also pointed out that many aspects of what Bryn Mawr does are replicable in other places. One of the main aspects is having wide-open doors that welcome all students. "Don't put students down if they don't achieve what you think they are supposed to," he said. "Find out what they are good at, and nurture that. Try to empower the students." Indeed, one of the biggest achievements of the Bryn Mawr math department has been its success in transforming attitudes towards mathematics in students who come in with the mindset that math is their worst subject.

The open-doors attitude is also appreciated by Bryn Mawr's math stars-like Jaclyn Lang. After graduating from Bryn Mawr, Lang received a Churchill fellowship to study mathematics at the University of Cambridge. Today she is pursuing a Ph.D. at the University of California, Los Angeles, supported by an NSF Graduate Fellowship. "The [Bryn Mawr] professors all care about the confused calculus and statistics students who come to their office hours just as they do the majors and graduate students with whom they discuss deeper mathematics," she said. "They listen to a student, figure out what she knows and what she struggles with, and then they think of a way to keep her challenged and interested in mathematics. The fact that they do this with students at all levels is what I find amazing, and I think this personal attention makes a huge impact on the students." 